Article

\title{
Application of Novel Anion-Exchange Blend Membranes (AEBMs) to Vanadium Redox Flow Batteries
}

\author{
Hyeongrae Cho ${ }^{1}$, Henning M. Krieg ${ }^{2}$ and Jochen A. Kerres ${ }^{1,2, *}$ \\ 1 Institute of Chemical Process Engineering, University of Stuttgart, 70199 Stuttgart, Germany; \\ Hyeongrae.cho@icvt.uni-stuttgart.de \\ 2 Faculty of Natural Science, North-West University, Focus Area: Chemical Resource Beneficiation, \\ Potchefstroom 2520, South Africa; henning.krieg@nwu.ac.za \\ * Correspondence: jochen.kerres@icvt.uni-stuttgart.de; Tel.: +49-711-68585-244
}

Received: 4 May 2018; Accepted: 14 June 2018; Published: 19 June 2018

\begin{abstract}
Both cation-exchange membranes and anion-exchange membranes are used as ion conducting membranes in vanadium redox flow batteries (VRFBs). Anion-exchange membranes (AEMs) are applied in vanadium redox flow batteries due to the high blocking property of vanadium ions via the Donnan exclusion effect. In this study, novel anion-exchange blend membranes (AEBMs) were prepared, characterized, and applied in VRFBs. Bromomethylated poly(2,6-dimethyl-1,4-phenylene oxide), poly[(1-(4,4'-diphenylether)5-oxybenzimidazole)-benzimidazole] (PBI-OO) and sulfonated polyether sulfone polymer were combined to prepare 3-component AEBMs with 1,2,4,5-tetramethylimidazole (TMIm) for quaternization. 3-component AEBMs showed significantly enhanced chemical and mechanical properties compared with those of 2-component AEBMs, resulting in an improved performance in VRFBs. The compositions of the anion-exchange polymers in 3-component AEBMs were systematically varied to optimize the AEBMs for the redox-flow battery application. While the 3-component AEBMs showed comparable efficiencies with Nafion ${ }^{\circledR} 212$ membranes, they displayed improved vanadium ions cross-over as was confirmed by open circuit voltage tests and capacity fade tests conducted in VRFBs. In addition, one of the synthesized 3-component AEBM had a superior coulombic efficiency and capacity retention in a charging-discharging test over 300 cycles at a current density of $40 \mathrm{~mA} / \mathrm{cm}^{2}$. It can thus be concluded that 3-component AEBMs are promising candidates for long-term operation in VRFBs.
\end{abstract}

Keywords: anion-exchange blend membrane; vanadium redox flow battery; vanadium ions cross-over; charging-discharging test; coulombic efficiency

\section{Introduction}

Vanadium redox flow batteries (VRFBs) provide a promising technology for large-scale energy storage. Vanadium redox flow batteries can be described as electrochemical devices that store energy in two separated solutions containing different redox couples. In VRFBs, vanadium ions, which are stored separately $\left(\mathrm{V}^{2+} / \mathrm{V}^{3+}\right.$ and $\left.\mathrm{V}^{4+} / \mathrm{V}^{5+}\right)$ in electrolyte reservoirs, undergo electrochemical redox reactions on the surface of electrodes [1,2]. Since ion conducting membranes are used in redox flow batteries (RFBs) as a separator between the two electrolytes, they are an integral component of VRFBs. Their role however is not only to conduct semi-permeable ions such as $\mathrm{H}^{+}$for cation-conducting membranes or $\mathrm{SO}_{4}{ }^{2-}$ and $\mathrm{HSO}_{4}{ }^{-}$for anion-conducting membranes thereby maintaining charge balance, but also to prevent the cross-mixing of the two electrolytes $\left(\mathrm{V}^{2+} / \mathrm{V}^{3+}\right.$ and $\left.\mathrm{V}^{4+} / \mathrm{V}^{5+}\right)$. 
For such VRFB separators, both cation-exchange membranes (CEMs) and anion-exchange membranes (AEMs) can be used. The most widely studied CEMs are based on perfluorinated polymer membranes known as Nafion ${ }^{\circledR}$ (developed by DuPont), which are commonly used in VRFBs because of their high proton conductivity and excellent chemical stability [3]. However, in VRFBs, Nafion ${ }^{\circledR}$ displays high vanadium ion permeation, resulting in fast capacity reduction in cycling tests [4]. To reduce the vanadium ions permeability, Nafion ${ }^{\circledR}$ has been modified both externally, for example by coating with polyethyleneimine [5], poly(diallyldimethylammonium chloride) (cationic layer), and poly(styrenesulfonic acid) (anionic layer) [6], or internally, for example by manufacturing composite membranes using inorganic particles [7,8]. However, in spite of these advances, Nafion ${ }^{\circledR}$ remains very expensive, limiting the large-scale commercialization of this technology [9]. For this reason, the development of alternative membranes for VRFBs has been intensively studied. For example, poly(vinylidene fluoride) (PVDF) membranes grafted onto polystyrene displayed better performances than Nafion ${ }^{\circledR}$ membranes [10]. In addition, aromatic main-chain polymers have been intensively studied due to their high chemical stability which can be traced back to their aromatic structure. One such polymer, sulfonated poly(ether ether ketone) (S-PEEK), when applied in VRFBs, has shown only a slight efficiency decrease after 80 charging-discharging cycles at $40 \mathrm{~mA} / \mathrm{cm}^{2}$ [11]. In contrast, sulfonated Radel ${ }^{\circledR}$-based polymer membranes suffered from significant capacity loss after 40 charging-discharging cycles at a current density of $50 \mathrm{~mA} / \mathrm{cm}^{2}$, probably due to a radical attack of highly-oxidizing vanadium oxoperoxide species on the electrophilic arylene ether bond [12,13]. Therefore, partially fluorinated aryl CEMs have been developed which possess lower electron density due to pendent strong electron-attracting $\mathrm{F}$ moieties, which leads to better stability resulting in improved efficiencies of RFBs [14,15].

Another strategy to improve the performance of VRFBs is using acid-base blend membranes composed of a sulfonated aryl polymer and a basic polymer with aryl group-based polymers [16]. These types of blend membranes, developed by the group of Dr. Kerres over more than 15 years of research, displayed improved chemical and mechanical stability compared to membranes consisting of homopolymers [17-19]. In terms of VRFBs, preliminary investigations of the performance of acid-base blend membranes showed higher efficiencies than that of Nafion ${ }^{\circledR}[16]$.

Most AEMs possess positively charged functional groups such as quaternized ammonium (fixed ions) with accompanying and exchangeable anions as counter ions. Through this structure, the positively charged vanadium ions are repulsed by the membrane, which is known as the Donnan exclusion effect, resulting in extremely low vanadium ions cross-over [20]. Low vanadium permeation is the reason for studying AEMs for VRFBs. For example, quaternized Diels-Alder poly(phenylene) membranes showed slower capacity fade than Nafion ${ }^{\circledR}$ [21]. Similarly, a quaternized ammonium functionalized poly(fluorenyl ether) AEM exhibited very low vanadium permeation and achieved $100 \%$ coulombic efficiency [22]. In another study, quaternized poly (phthalazinone ether ketone ketone) membranes were prepared and investigated for VRFB suitability showing almost $100 \%$ coulombic efficiency at a charging-discharging test for 80 cycles measured at a current density of $80 \mathrm{~mA} / \mathrm{cm}^{2}$ [23]. Recently, polysulfone-based cross-linked AEMs were applied in VRFBs also showing coulombic efficiencies of $100 \%$ after 100 cycles at $50 \mathrm{~mA} / \mathrm{cm}^{2}$ indicating excellent blocking of vanadium ions [24]. Ren et al. [25] investigated blend membranes of quaternized polysulfone/polyvinylidene fluoride (PVDF) showing improved mechanical properties and performance in VRFBs due to blending. Various studies have investigated the use of amphoteric membranes via acid-base blending for VRFBs [26,27]. Again these blend membranes showed high coulombic efficiencies where the capacity retention for long-time cycling from one of the ImPSf/SPEEK blend membranes was $69 \%$ at the 50 th cycle measured at a current density of $80 \mathrm{~mA} / \mathrm{cm}^{2}$ while blend membranes prepared from sulfonated poly(ether ether ketone) and quaternized poly(ether imide) reached $64 \%$ at the 100 th cycle measured at a current density of $50 \mathrm{~mA} / \mathrm{cm}^{2}$.

As mentioned previously, blend membranes according to the literature showed improved VRFB performance compared to homopolymer membranes. Previously, results obtained from 
2-component blend membranes were published indicating improved performance as aforementioned. In this study, 3-component polymer containing anion-exchange blend membranes (AEBMs) were prepared and characterized in terms of the physical properties, chemical stability, and performance in VRFBs. For the 3-component blend membranes, bromomethylated poly(2,6-dimethyl-1,4-phenylene oxide) (Br-PPO) was used as an anion-exchange precursor with 1,2,4,5-tetramethylimidazole (TMIm), and poly[(1-(4,4'-diphenylether)-5-oxybenzimidazole)-benzimidazole] (PBI-OO) being used as a matrix polymer to improve the mechanical stability. A small amount of a sulfonated polymer ( 9 to $15 \%$ in blend membranes) was added as a third polymer component for ionical cross-linking. The 3-component anion-exchange blend membranes showed significantly improved VRFB performance regarding vanadium ion cross-over when compared to 2-component blend membranes containing only $\mathrm{PPO}-\mathrm{Br}$ and PBI-OO. One of the 3-component anion-exchange blend membranes did not show any changes in coulombic efficiency during 300 cycles maintaining almost $100 \%$. At the 300th cycle performed at the current density of $40 \mathrm{~mA} / \mathrm{cm}^{2}, 77 \%$ of capacity had remained. The anion-exchange blend membrane showed significantly longer stability during the open circuit voltage (OCV) test due to the lower vanadium ions cross-over when compared to commercial membranes. Accordingly, the anion-exchange blend membranes would be promising candidates for long-term operation in VRFB applications.

\section{Materials and Methods}

\subsection{Materials}

All chemicals were used without further purification. Poly(2,6-dimethyl-1,4-phenylene oxide) (PPO) was purchased from Sigma Aldrich (Munich, Germany), and bromination was conducted in the same way as described previously [28]. Poly[(1-(4,4'-diphenylether)-5 -oxybenzimidazole)-benzimidazole] (PBI-OO) was purchased from FuMA-Tech GmbH (Ludwigsburg, Germany). Sulfonated polymer was synthesized as previously reported in the literature [29]. 1,2,4,5-tetramethylimidazole was purchased from TCI chemicals. N,N-Dimethylacetamide (DMAc) and methanol were obtained from VWR International GmbH (Bruchsal, Germany). Sulfuric acid, potassium hydroxide, $0.1 \mathrm{~N}$ standard hydrochloric acid, and sodium hydroxide were purchased from Carl Roth GmbH (Karlsruhe, Germany). Vanadium electrolyte was provided by RIVA GmbH Batteries. The structures used in this study are presented in Figure 1.

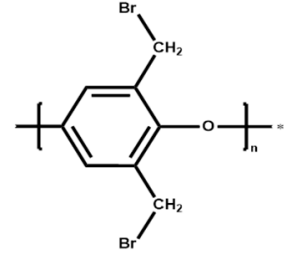

Bromomethylated PPO

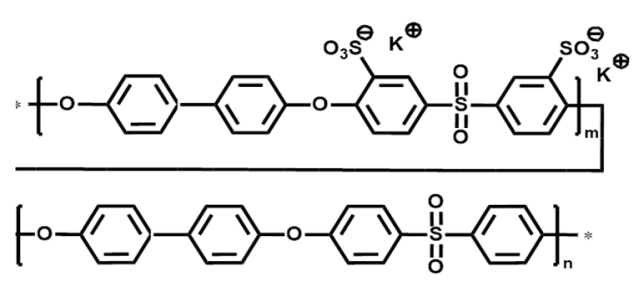

Sulfonated polymer<smiles></smiles><smiles>Cc1nc(C)n(C)c1C</smiles>

Figure 1. Structures of polymers and TMIm used in this study. 


\subsection{Membranes Preparation}

Details of the preparation of the anion-exchange blend membranes are shown in Figure 2. Each polymer solution was prepared separately as a $10 \mathrm{wt} \%$ solution in DMAc. Polymer solutions were mixed together, then TMIm was added in to the polymer mixture solution directly in the desired quantities and homogenized. The blend solution was then casted onto a glass plate, followed by solvent evaporation in a convection oven (pre-heated at $40{ }^{\circ} \mathrm{C}$ ) at $60{ }^{\circ} \mathrm{C}$ for $24 \mathrm{~h}$. After drying, the formed membrane was separated from the glass plate by immersion in water. Then membranes were immersed in $1 \mathrm{M}$ sulfuric acid for 1 day at room temperature with one replacement of the sulfuric acid solution during this period. The membranes were repeatedly washed with deionized water at room temperature for 1 day to remove all excess sulfuric acid before being stored in plastic zipper bags before further use.

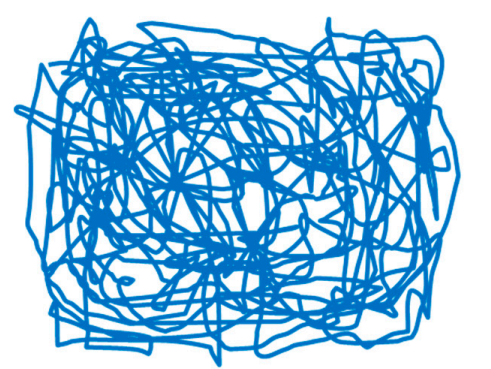

Matrix polymer (PBI)

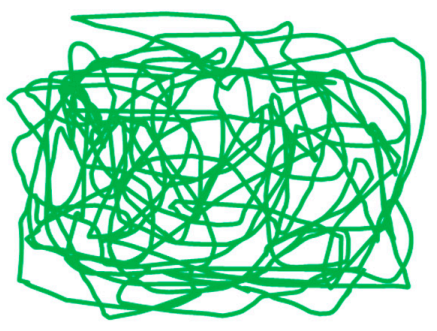

Anion exchange ionomer precursor

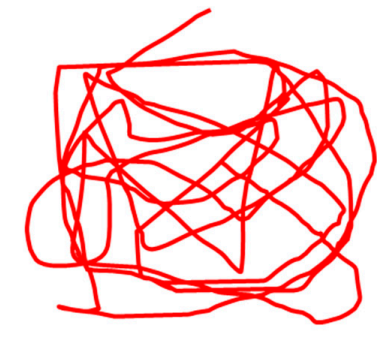

Sulfonated polymer

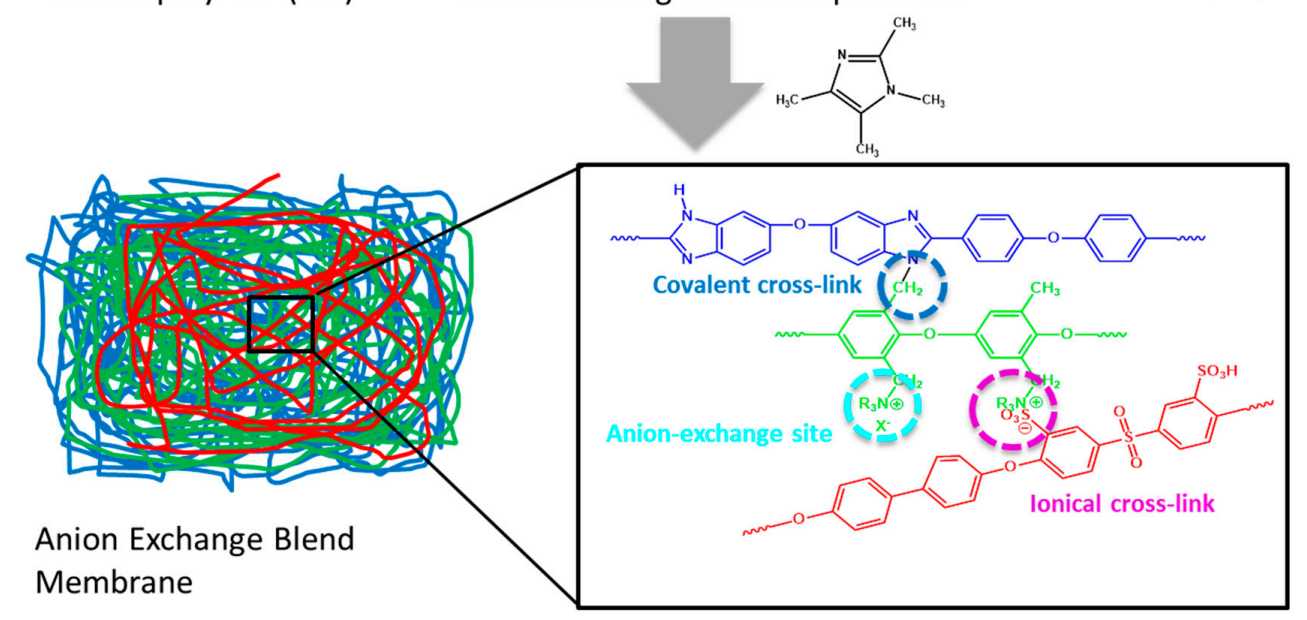

Figure 2. Preparation of anion-exchange blend membranes.

\subsection{Membrane Characterization}

\subsubsection{Ion Exchange Capacity}

The membranes were immersed in a $1 \mathrm{M} \mathrm{KOH}$ solution for 1 day at $90^{\circ} \mathrm{C}$ for ion exchange to hydroxide form. After ion exchange, the membranes were washed with water several times to remove excess $\mathrm{KOH}$. Subsequently, the membranes were immersed in a $60 \mathrm{~mL}$ saturated sodium chloride solution to exchange the anion-exchange groups to chloride and stirred for 1 day. Subsequently, $3 \mathrm{~mL}$ of a standard $0.1 \mathrm{~N}$ hydrochloric acid was added to the saturated sodium chloride solution and stored overnight. The next day, the membranes were washed with $25 \mathrm{~mL}$ deionized water and this water was added to the $60 \mathrm{~mL}$ saturated sodium chloride solution. The back titration was conducted with a $0.1 \mathrm{~N}$ sodium hydroxide solution. Finally, the membrane was repeatedly washed with water and dried at 60 ${ }^{\circ} \mathrm{C}$. The total IEC was calculated using the following equation.

$$
\mathrm{IEC}=\left(\mathrm{C}_{\mathrm{HCl}} \times \mathrm{V}_{\mathrm{HCl}}-\mathrm{C}_{\mathrm{NaOH}} \times \mathrm{V}_{\mathrm{NaOH}}\right) / \mathrm{m}_{\mathrm{dry}}
$$


where IEC is the ion exchange capacity ( $\mathrm{OH}$ form, $\mathrm{mmol} / \mathrm{g}), \mathrm{C}_{\mathrm{HCl}}$ is the concentration of a hydrochloric acid solution, $\mathrm{V}_{\mathrm{HCl}}$ is the used volume of a hydrochloric acid solution, $\mathrm{C}_{\mathrm{NaOH}}$ is the concentration of a sodium hydroxide solution, $\mathrm{V}_{\mathrm{NaOH}}$ is the added volume of a sodium hydroxide solution, and $\mathrm{m}_{\mathrm{dry}}$ is the dry weight of the membrane.

\subsubsection{Conductivity}

A Zahner-elektrik IM6 impedance spectrometer (Kronach, Germany) was used for measuring impedance under ambient atmosphere. The impedance was recorded at room temperature in a $1 \mathrm{M}$ sulfuric acid solution with a frequency range of $200 \mathrm{KHz}$ to $8 \mathrm{MHz}$ in the potentiostatic mode (amplitude $10 \mathrm{mV}$ ). The membrane resistance was obtained from the intercept in the real $\mathrm{X}$-axis. The conductivity was determined using the follow equation.

$$
\sigma=1 / R_{\mathrm{sp}}=\mathrm{d} / \mathrm{R} \times \mathrm{A}
$$

where $\sigma$ is the conductivity $(\mathrm{mS} / \mathrm{cm}), R_{\text {sp }}$ is the resistivity $(\Omega \mathrm{cm}), d$ is the thickness of membrane $(\mathrm{cm})$, $\mathrm{R}$ is the ohmic resistance $(\Omega)$, and A is the electrode area $\left(\mathrm{cm}^{2}\right)$

\subsubsection{Water Uptake (WU) and Swelling Ratio (SR)}

The water uptake and swelling ratio were determined by comparing the membrane weight, length, width, and thickness of a dry and a wetted membrane. A wet membrane sample was cut and the weight, length, width, and thickness was measured after removal of residual water on the surface by blotting with a tissue paper. After drying the membrane at $90{ }^{\circ} \mathrm{C}$ for 1 day, the weight, length, width, and thickness were again measured. The water uptake and swelling ratio were calculated using the following equations.

$$
\begin{gathered}
\text { WU }(\%)=(\text { Wet weight }- \text { Dry weight }) / \text { Dry weight } \times 100 \\
\mathrm{SR}_{\mathrm{L}}(\%)=(\text { Wet length }- \text { Dry length }) / \text { Dry length } \times 100 \\
\mathrm{SR}_{\mathrm{W}}(\%)=(\text { Wet width }- \text { Dry width }) / \text { Dry width } \times 100 \\
\mathrm{SR}_{\mathrm{T}}(\%)=(\text { Wet thickness }- \text { Dry thickness }) / \text { Dry thickness } \times 100
\end{gathered}
$$

\subsubsection{Fourier-Transform Infrared Spectroscopy (FT-IR)}

FT-IR spectra of the membranes were recorded comprising 64 scans in the wave number range from 4000 to $400 \mathrm{~cm}^{-1}$ using a Nicolet iS5 (Thermofisher Scientific, Karlsruhe, Germany) and a diamond attenuated total reflectance (ATR) module.

\subsubsection{Gel Content by Extraction}

To determine the degree of dissolution of the membrane in an organic solvent, the weight loss was calculated by measuring the weight difference of the membranes before and after DMAc extraction. The dry membrane was kept in DMAc for 4 days at $90{ }^{\circ} \mathrm{C}$ and the following 3 days in methanol. The weight loss was determined using the following equation.

$$
\text { Gel }(\%)=(\text { Weight after } / \text { Weight before }) \times 100
$$

\subsubsection{Thermal Stability}

To investigate the thermal stability of the membrane, thermal gravimetric analysis (TGA) was done using a dried membrane (dried at $90{ }^{\circ} \mathrm{C}$ in convection oven) at a heating rate of $20{ }^{\circ} \mathrm{C}$ per minute under $\mathrm{O}_{2} / \mathrm{N}_{2}$ atmosphere (65-70\% oxygen) with a NETZSCH TGA, model STA 499C (Selb, Germany). 


\subsubsection{Chemical Stability}

The chemical stability of the membrane was determined using an electrolyte solution $(1.6 \mathrm{M}$ $\mathrm{VOSO}_{4}$ in $30 \% \mathrm{H}_{2} \mathrm{SO}_{4}$ ). A dry membrane was soaked in this solution at room temperature for 12 days. Subsequently, the membrane was washed repeatedly with water for 1 day before being dried at $90^{\circ} \mathrm{C}$ in an oven. The weight loss (WL) of the membrane was determined using the following equation.

$$
\text { WL }(\%)=[(\text { Weight before }- \text { Weight after }) / \text { Weight before }] \times 100
$$

\subsection{Vanadium Redox Flow Battery (VRFB) Test}

A VRFB single cell was manufactured as shown in Figure 3. The anion-exchange blend membrane with an active area of $28 \mathrm{~cm}^{2}$ was placed between two carbon felts. Copper plates were used as a current collector. The single cell was assembled between two end plates, and the screws were fastened with a torque of $3.5 \mathrm{Nm}$. Polyethylene tubes were utilized to supply the electrolytes. Twenty $\mathrm{mL}$ of $1.6 \mathrm{M} \mathrm{VOSO}_{4}$ in $30 \% \mathrm{H}_{2} \mathrm{SO}_{4}$ was filled in tubes of both sides as electrolytes, without pumps and tanks. The cell was first charged to $1.6 \mathrm{~V}$ at $40 \mathrm{~mA} / \mathrm{cm}^{2}$ and discharged to $1.0 \mathrm{~V}$ at the same current density, then charged and discharged at different current densities. The open circuit voltage $(\mathrm{OCV})$ was recorded after charging the cell to $1.6 \mathrm{~V}$. A long-term charging-discharging cycles test was conducted with a current density of $40 \mathrm{~mA} / \mathrm{cm}^{2}$. The coulombic efficiency (CE), voltage efficiency (VE), and energy efficiency (EE) for the process were calculated as follows.

$$
\begin{gathered}
\operatorname{CE}(\%)=t_{d} / t_{c} \times 100 \\
\operatorname{VE~}(\%)=V_{d} / V_{c} \times 100 \\
\operatorname{EE~}(\%)=C E \times V E \times 100
\end{gathered}
$$

where $t_{d}$ is the discharging time, $t_{c}$ is the charging time, $V_{d}$ is the average discharging voltage, and $V_{c}$ is the average charging voltage.

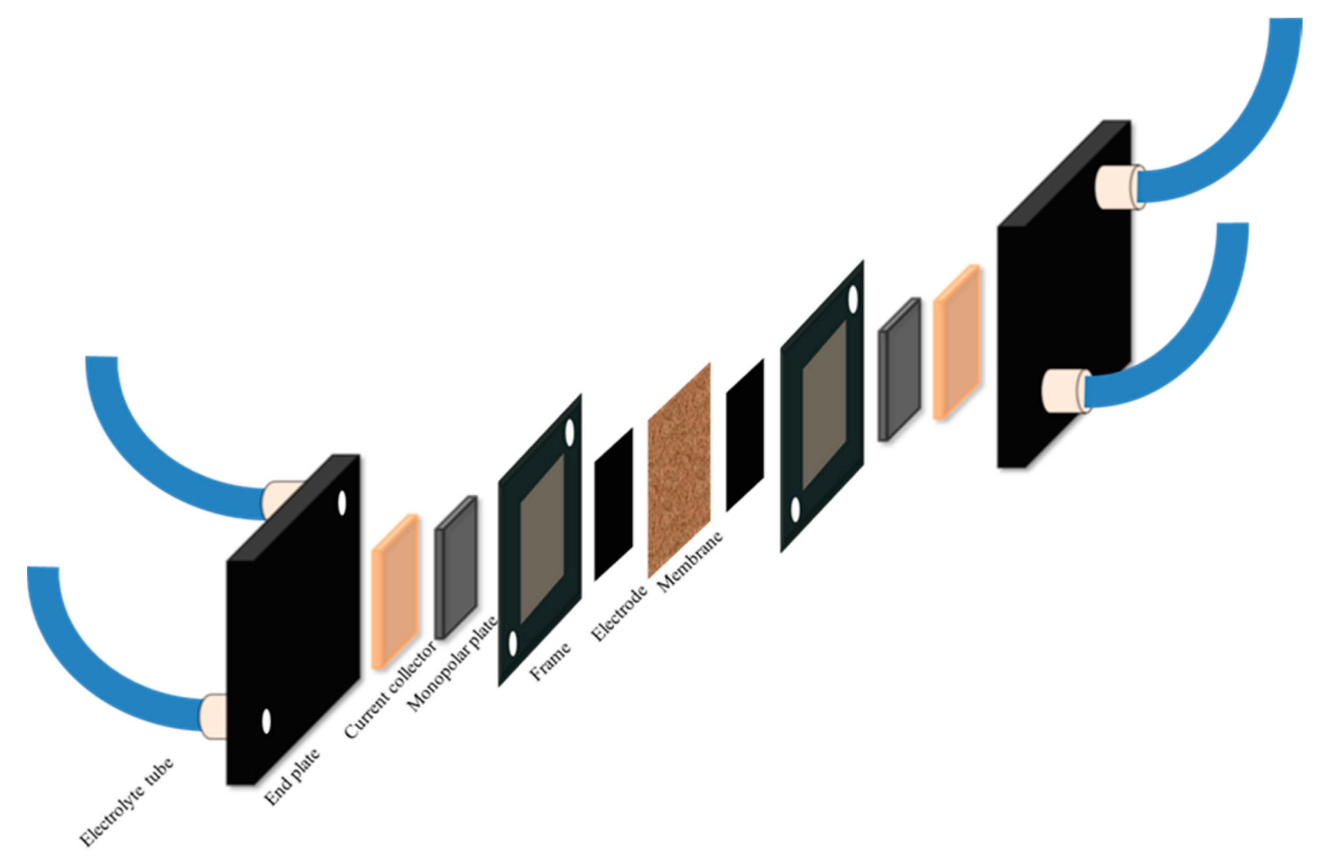

Figure 3. The configuration of vanadium redox flow battery single cell. 


\section{Results and Discussion}

\subsection{Preparation and Properties of Anion-Exchange Blend Membranes}

Anion-exchange blend membranes composed of two or three polymeric components which had been quaternized with TMIm were prepared. Details of the membranes and their compositions are listed in Table 1. PBI-OO was used as a matrix polymer since polybenzimidazoles are known to possess high mechanical and thermal stabilities [30]. The mechanical stability was further enhanced in the blend system by the covalent cross-linking with Br-PPO [31,32], as shown in Figure 2. Br-PPO was used as an anion-exchange precursor, and the anion-exchange polymer was formed by quaternization of the bromomethyl groups of Br-PPO with TMIm. A sulfonated polymer was used as an ionical cross-linker (sulfonate anions with tetramethylimidazolium cations).

Table 1. The compositions of the anion-exchange blend membranes.

\begin{tabular}{|c|c|c|c|c|}
\hline Entry & Br-PPO **/wt \% & PBI-OO ***/wt \% & S-Polymer ***/wt \% & TMIm $* * * *$ (Equivalent) \\
\hline BM-TMIm * 1 & 52 & 35 & 13 & 3 \\
\hline BM-TMIm 1-1 & 52 & 35 & 13 & 1 \\
\hline BM-TMIm 2 & 60 & 26 & 15 & 1 \\
\hline BM-TMIm 4 & 45 & 45 & 11 & 1 \\
\hline BM-TMIm 5 & 36 & 55 & 9 & 1 \\
\hline BM-TMIm 6 & 60 & 40 & 0 & 1 \\
\hline
\end{tabular}

Initially the anion-exchange blend membranes were made using an excess of TMIm (BM-TMIm 1), but the membranes showed turbidity after solvent evaporation. Moreover, they were mechanically unstable when wet due to high water uptake (Figure S1). Thus, the amount of TMIm was reduced to the same equivalent of Br-PPO (except for BM-TMIm 1-see Table 1) resulting in transparent membranes after solvent evaporation and mechanical stability of the water-swollen membranes. Anion-exchange blend membranes were prepared with different ratios between the PBI-OO and Br-PPO. It was subsequently observed that BM-TMIm 2 (Br-PPO:PBI-OO $=7: 3$ by wt $\%$ ) was a turbid membrane when dry and mechanically not very stable. Transparent and mechanically stable blend membranes were obtained by reducing the anion-exchange polymer (i.e., Br-PPO amounts). It turned out that blend membranes containing high amounts (more than 52\%) of TMIm-quaternized PPO yielded turbid membranes after solvent evaporation, being mechanically instable when wet. It should be noted that the blend membrane composed of Br-PPO and PBI-OO (6:4 by weight percent) without TMIm showed very low conductivity $(0.41 \mathrm{mS} / \mathrm{cm}$ in $1 \mathrm{M}$ sulfuric acid) and no performance in the VRFBs test, thus, blend membranes in this study, mostly from quaternized groups originated from the quaternization reaction of Br-PPO with TMIm.

A structural analyses of the three individual polymers (Br-PPO, S-polymer, PBI-OO) used as well as on one membrane (BM-TMIm 1) were performed using FT-IR (ATR mode) as presented in Figure 4. According to the literature, the peaks of the imidazolium-quaternized PPO were found at 1573, 752, and $3400 \mathrm{~cm}^{-1}$ [33]. These peaks are found in blend membranes (Figure S2). However, in the blend membranes these peaks overlap with other polymer peaks and were hence not clearly recognizable. The stretching vibration peaks of the $\mathrm{CH}_{2} \mathrm{Cl}$ group in poly(vinylbenzyl chloride) were found at 675, 709 , and $1267 \mathrm{~cm}^{-1}$ [34]. Thus, the strong peak at $1302 \mathrm{~cm}^{-1}$ in Br-PPO in Figure 4 can be assigned as a stretching vibration of the $\mathrm{CH}_{2} \mathrm{Br}$ group, which is not found in the blend membranes, indicating that no bromomethyl groups were left in the blend membranes after quaternization.

A summary of the properties of the membranes is listed in Table 2. All synthesized anion-exchange blend membranes in this study showed comparable IECs with other published results [35]. It is known 
that the conductivity of anion-exchange membranes is much lower than proton conductivity of cation-exchange membranes in aqueous solution [22]. Both BM-TMIm 1 and BM-TMIm 2 showed higher ionic conductivities (149 and $144 \mathrm{mS} / \mathrm{cm}$, respectively) than Nafion ${ }^{\circledR}(98.5 \mathrm{mS} / \mathrm{cm})$ in acidic media (1 M sulfuric acid), which can be ascribed to the high uptake of sulfuric acid contributing to ionic conductivity. This confirms that conductivities can be achieved that are comparable to cation-exchange membranes. Therefore, the disadvantage of the low conductivity of AEMs can be overcome by adjusting the IECs and electrolyte uptakes when applied in VRFBs, since contribution of conductivity in AEMs is sulfate anions and protons. But in the PEMs, some of the anionic sites are occupied by low mobility vanadium anions [36]. With increasing Br-PPO content in the blend membranes, the conductivity increased while the dimensional stability decreased due to the increased water uptake. The addition of the sulfonated polymer resulted in decreased conductivities but enhanced dimensional stability and higher gel content (see data of BM-TMIm 1-1 and BM-TMIm 6 in Table 2). Thus swelling properties of the anion-exchange blend membranes can be controlled by varying the anion-exchange polymer percent and/or addition of a sulfonated polymer, where a tradeoff has to be sought between the swelling degree and the ionic conductivity.

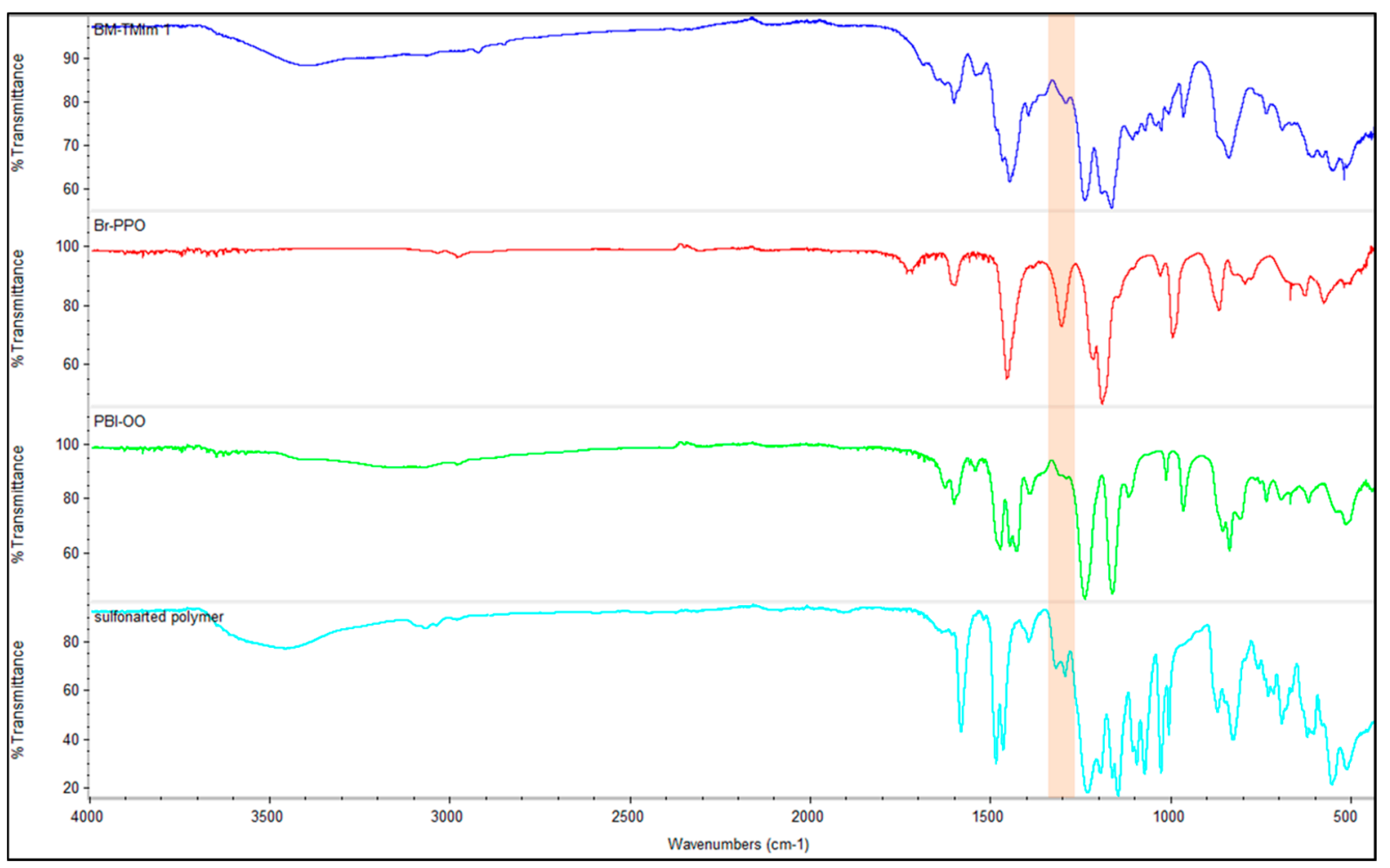

Figure 4. Fourier-Transform Infrared (FT-IR) spectrum of blend-forming polymers and of one anion-exchange blend membrane as an example (BM-TMIm 1).

Table 2. The properties of anion-exchange blend membranes.

\begin{tabular}{|c|c|c|c|c|c|c|c|c|c|}
\hline \multirow{2}{*}{ Entry } & \multirow{2}{*}{ IECs (OH Form) } & \multirow{2}{*}{$\begin{array}{l}\text { Conductivities } \\
(\mathrm{mS} / \mathrm{cm})\end{array}$} & \multirow{2}{*}{ Gel (\%) } & \multicolumn{4}{|c|}{ Dimensional Stability } & \multirow{2}{*}{$\begin{array}{c}\mathrm{T}_{\text {onset }} \\
\left({ }^{\circ} \mathrm{C}\right)\end{array}$} & \multirow{2}{*}{$\begin{array}{l}\text { Thickness }(\mu \mathrm{m}, \text { Wet } \\
\left.\text { in } 1 \mathrm{M} \mathrm{H}_{2} \mathrm{SO}_{4}\right)\end{array}$} \\
\hline & & & & WU (\%) & $\mathrm{SR}_{\mathrm{L}}(\%)$ & $\mathrm{SR}_{\mathrm{W}}(\%)$ & $\mathrm{SR}_{\mathrm{T}}(\%)$ & & \\
\hline BM-TMIm 1 & 2.71 & 149 & 95 & 71 & 31 & 29 & 16 & 281 & 89 \\
\hline BM-TMIm 1-1 & 3.26 & 40.9 & 95 & 47 & 19 & 18 & 15 & 314 & 71 \\
\hline BM-TMIm 2 & 3.04 & 144 & 94 & 105 & n. a. $* *$ & n. a. $* *$ & n. a. ${ }^{* *}$ & 320 & 92 \\
\hline BM-TMIm 4 & 3.41 & 21.0 & 94 & 31 & 12 & 12 & 9 & 306 & 57 \\
\hline BM-TMIm 5 & 2.93 & 13.7 & 92 & 33 & 12 & 11 & 8 & 306 & 66 \\
\hline BM-TMIm 6 & 3.39 & 65.2 & 92 & 58 & 21 & 20 & 15 & 303 & 63 \\
\hline FAP 450 * & 2.18 & 35.2 & $-* * *$ & 19 & 9 & 8 & 9 & 304 & 58 \\
\hline Nafion ${ }^{\circledR} 212$ & 0.88 (H form $)$ & 98.5 & - & 8 & 7 & 9 & 3 & 299 & 53 \\
\hline
\end{tabular}

* FAP 450: anion-exchange membrane produced by Fuma-Tech; ${ }^{* *}$ not applicable due to mechanical failure; *** extremely swelling in DMAc. 
The thermal stability of the blend membranes as determined using thermal gravimetric analysis (TGA) is shown in Figure 5. The first weight loss step $\left(50-150^{\circ} \mathrm{C}\right)$ is attributed to the water evaporation absorbed in the membranes. The second step starts at $300{ }^{\circ} \mathrm{C}$, which is due to the loss of quaternized imidazolium groups and splitting-off of the sulfonate groups of the sulfonated blend component [37]. Thus, thermal stabilities of 2-component (BM-TMIm 6, $303{ }^{\circ} \mathrm{C}$, loss of quaternized imidazolium) and 3-component (BM-TMIm 1-1, $314{ }^{\circ} \mathrm{C}$, loss of quaternized imidazolium and sulfonated group) blend membranes showed similar thermal stabilities. It is clear from the TGA traces that all the anion-exchange blend membranes had excellent thermal stabilities.

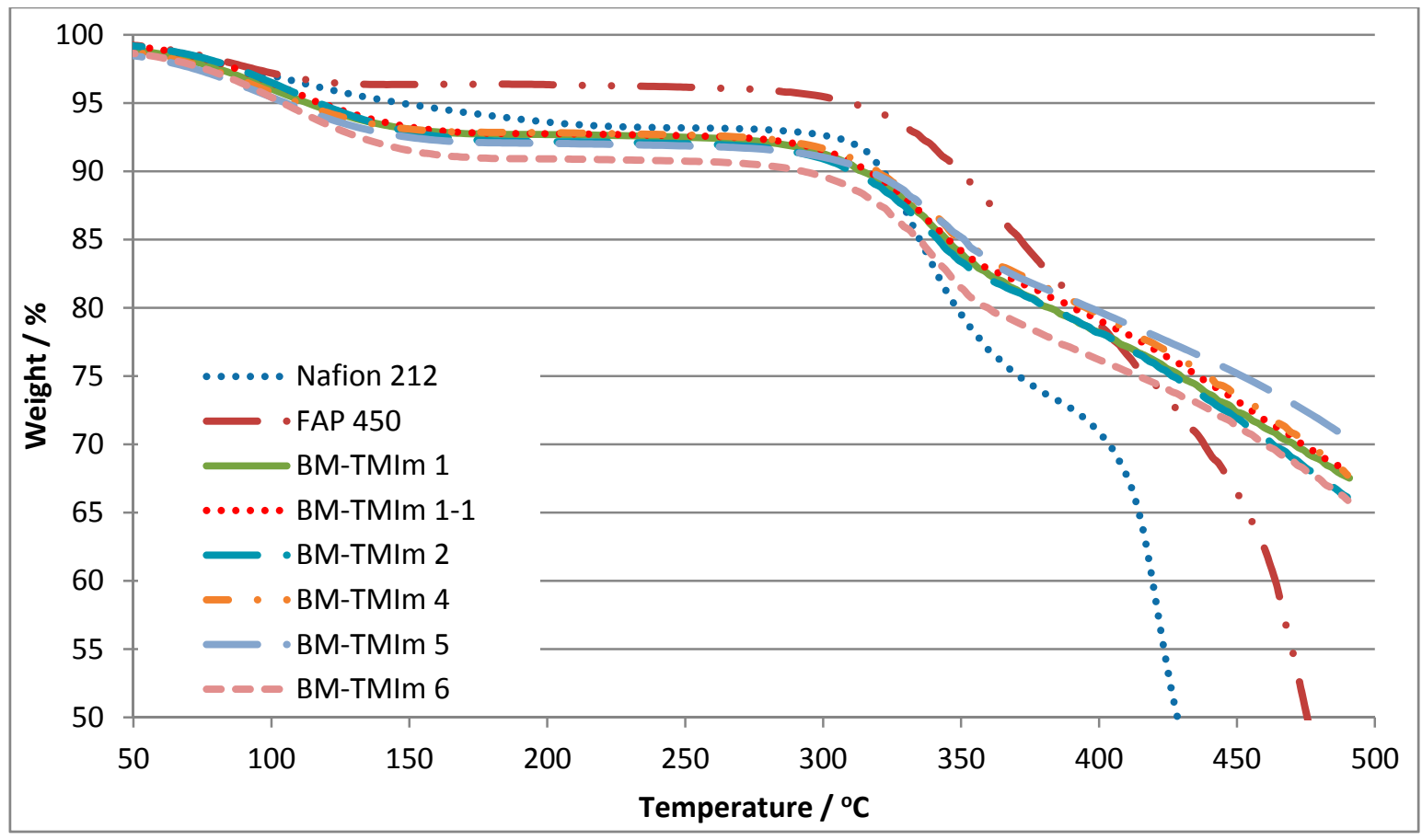

Figure 5. Thermal gravimetric analysis (TGA) traces of membranes in comparison to FAP 450 (anion-exchange membrane produced by Fuma-Tech) and to Nafion ${ }^{\circledR} 212$.

By comparing the weight variation of membranes after immersion in electrolyte solution, the relative chemical stability can be evaluated [38]. According to the literature, the proposed degradation pathway for membranes is based on aromatic backbone degradation caused by vanadium peroxo radicals resulting in chain-scission and weight loss by leaching out the degraded polymer chains of the blend components [13]. For the chemical stability test, the membranes were immersed in an electrolyte solution $\left(1.6 \mathrm{M} \mathrm{VOSO}_{4}\right.$ in $\left.30 \% \mathrm{H}_{2} \mathrm{SO}_{4}\right)$ at room temperature for 12 days. The weight losses before and after the test are shown in Figure 6. All the blend membranes showed weight losses in the range of $5 \%$ to $8 \%$ which is higher than the weight loss of $\mathrm{Nafion}^{\circledR}$ which had an outstanding chemical stability due to its perfluorinated alkyl backbone. The weight loss of the commercial anion-exchange membrane FAP 450 lies in the same range as these of the AEBMs. It can be seen that the 3-component blend membranes (e.g., BM-TMIm 1-1, 5.2\%) showed less weight loss than the 2-component blend membrane (BM-TMIm 6, 7.8\%). These two membranes are comparable as they were prepared with the same amount of Br-PPO and PBI-OO, with only the sulfonated polymer added in BM-TMIm 1-1 confirming that the additional sulfonated polymer enhanced the chemical stability and mechanical stability. 


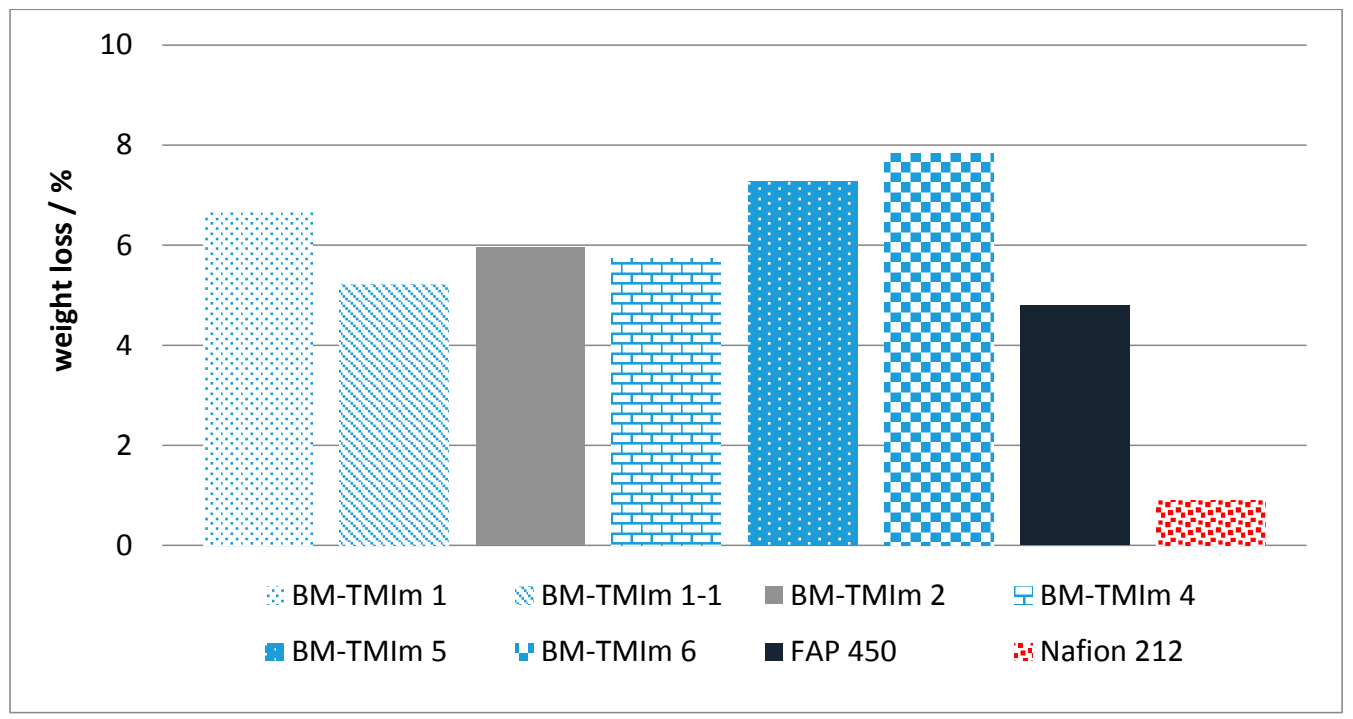

Figure 6. Weight losses after soaking in electrolyte solution at room temperature for 12 days.

\subsection{Vanadium Redox Flow Battery Performance}

The upper limit charge voltage of the single cell was set to $1.6 \mathrm{~V}$ to avoid corrosion of the electrodes [39]. The performance of the different membranes was recorded using a single VRFB cell. Due to mechanical membrane failure during single cell preparation (broken, BM-TMIm 1) and a very fast cross-over of electrolyte (BM-TMIm 2) in the VRFB caused by high water uptake and therefore low dimensional stabilities of blend membranes, the performance of BM-TMIm 1 and BM-TMIm 2 were not further measured in battery tests. Figure $7 \mathrm{a}-\mathrm{c}$ shows the respective $\mathrm{CE}, \mathrm{VE}$, and EE of the VRFB as a function of the current density. In general, the CE of VRFBs is influenced by vanadium ions permeation, possible side reactions, and electrode corrosion [40]. Since the VRFB setup was identical for all single cell performance measurements in this study, the side reactions and electrode corrosion should be similar for all battery measurements. Therefore, the main contribution to the CE is the vanadium ions cross-over.

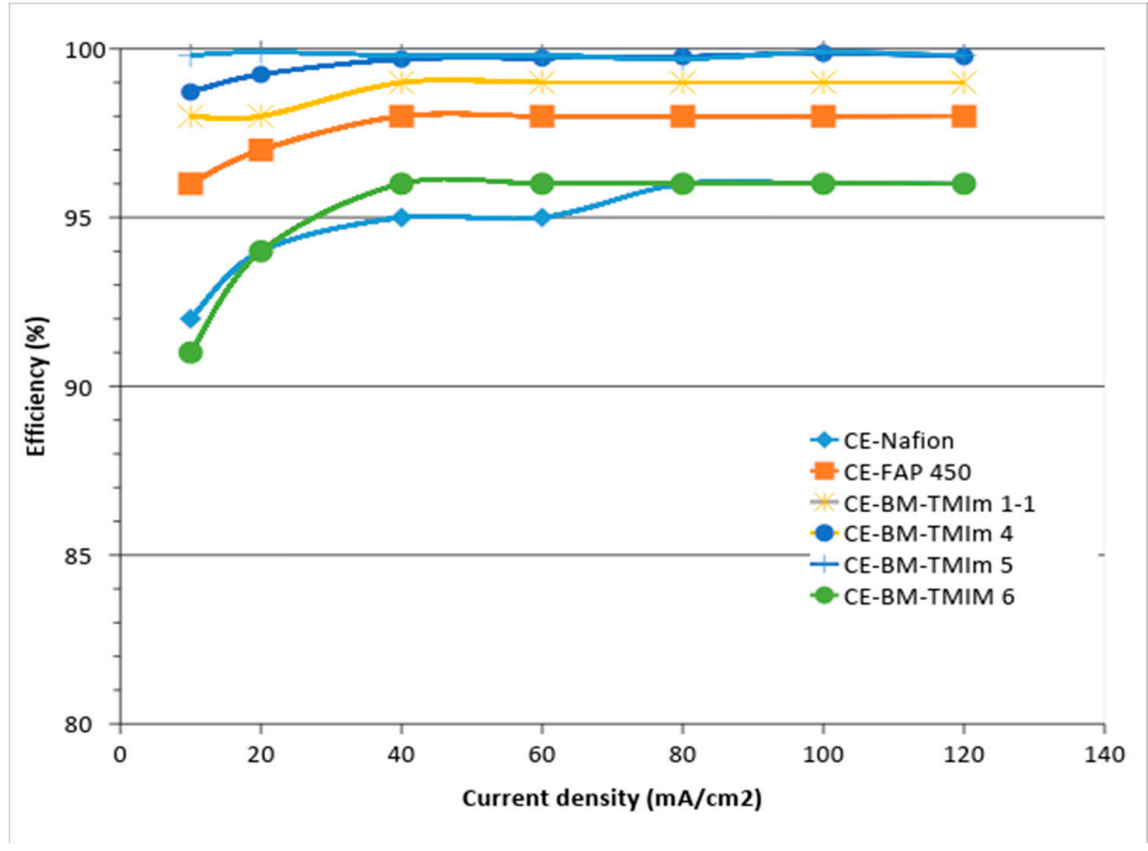

(a)

Figure 7. Cont. 


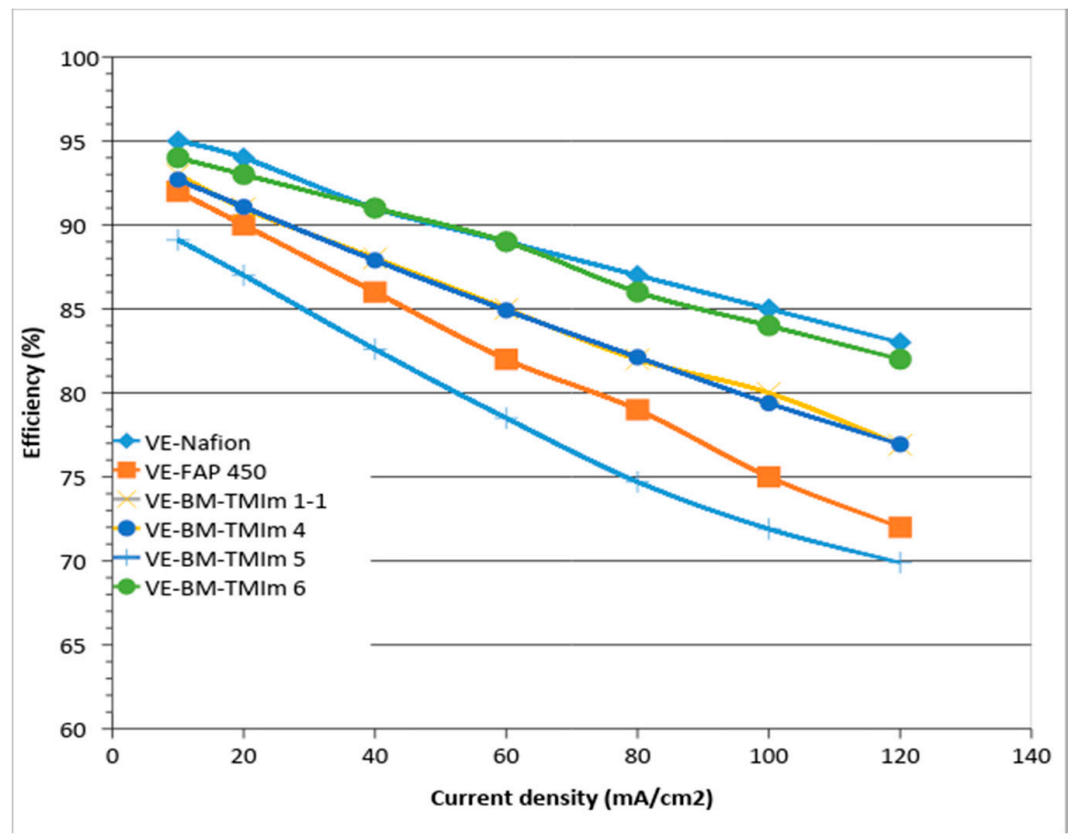

(b)

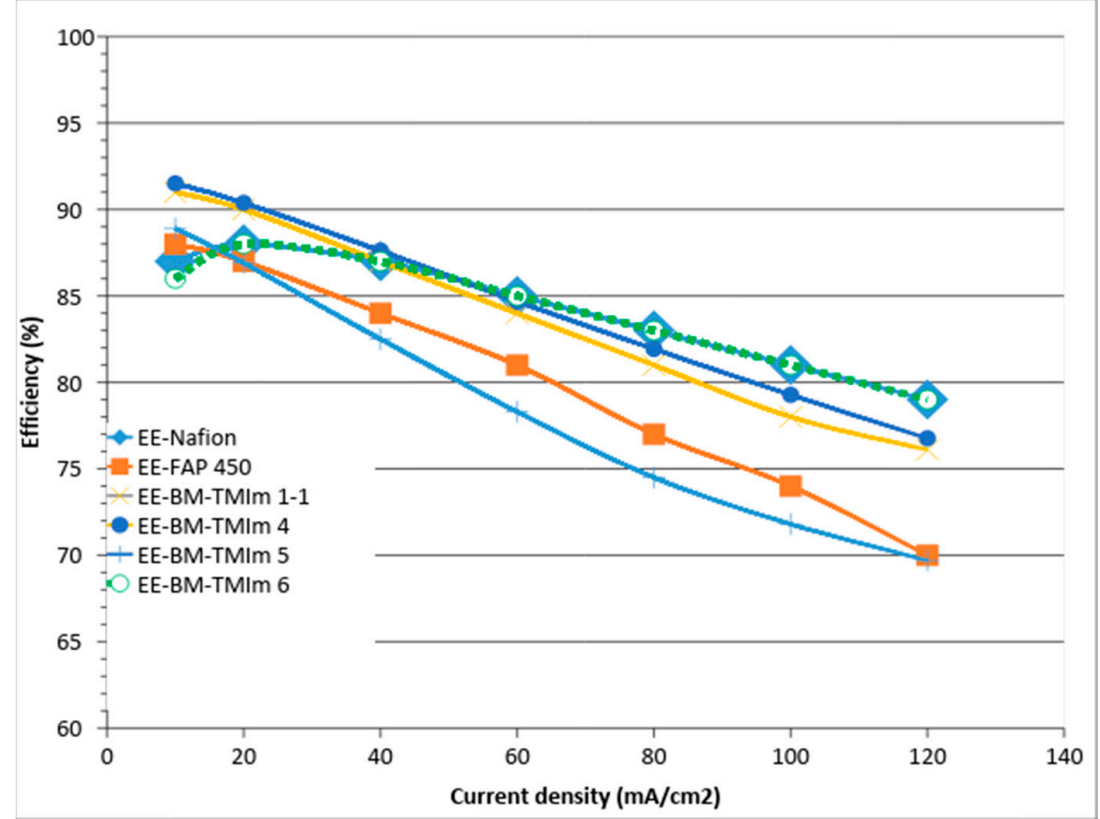

(c)

Figure 7. Coulombic efficiency (CE) (a); voltage efficiency (VE) (b); and energy efficiency (EE) (c) of different membranes in VRFBs at various current densities.

All anion-exchange blend membranes have shown higher CEs than Nafion ${ }^{\circledR}$ due to the Donnan exclusion effect mentioned previously. The 3-component AEBMs had a higher $\mathrm{CE}$ than the 2-component AEBMs in VRFBs indicating less vanadium ions cross-over via enhanced dimensional stability. These membranes also showed an increased $\mathrm{CE}$ as a function of current density due to the decreased time allowed for vanadium permeation. Hence the 3-component AEBMs had improved vanadium ions blocking properties than the 2-component AEBMs. The VE of all membranes decreased with increasing current density due to the increasing over voltage at the electrodes [41]. The VE is affected by the ohmic resistance which corresponds to the ionic conductivity [40]. Nafion ${ }^{\circledR}$, as expected, showed the highest VE of all the tested membranes in VRFBs due to its high cation conductivity and BM-TMIm 5 showed 
lowest VE due to the lowest conductivity among the tested membranes. However, it can be seen that the differences of the VEs between BM-TMIm 1-1 or BM-TMIm 4 and Nafion ${ }^{\circledR}$ were small despite the higher conductivity of Nafion ${ }^{\circledR} 212$, compared to that of most of the blend membranes. Moreover, VEs of BM-TMIm 1-1 and BM-TMIm 4 showed almost the same value despite the higher conductivity of BM-TMIm 1-1, compared to that of BM-TMIm 4. These results suggest that the ionic conductivity in VRFBs is not a critical parameter. The overall energy efficiencies (EE) of AEBMs showed higher values than that of FAP 450 and comparable values to Nafion ${ }^{\circledR}$ irrespective of the current densities. The EE of BM-TMIm 4 was slightly higher than that of Nafion ${ }^{\circledR}$ below a current density of $50 \mathrm{~mA} / \mathrm{cm}^{2}$, which allows the conclusion that this membrane should be operated in a VRFB at moderate current densities.

Open circuit voltage measurements of VRFBs are often used as an indirect method to investigate the vanadium ions cross-over [27]. Hence, a self-discharge test was run by measuring the OCV as a function of time (Figure 8). It is clear that complete cross-over of vanadium ions through the membranes cannot be avoided because of the diffusion of vanadium ions through the membranes caused by different concentrations of vanadium ion oxidation states between the two electrolytes [42]. In all cases, a sudden OCV drop was observed which can be explained by the disappearance of $\mathrm{VO}_{2}{ }^{+}$ in the positive electrolyte originating from vanadium ions cross-over. Firstly, the single cell was charged to $1.6 \mathrm{~V}$ with a current density of $40 \mathrm{~mA} / \mathrm{cm}^{2}$ followed immediately by the self-discharge test. While most membranes, including the commercial membranes, showed a sudden drop before $40 \mathrm{~h}$, BM-TMIm 4 had a drop off only after $184.3 \mathrm{~h}$ correlating with results of coulombic efficiency originating from the reduced vanadium ions cross-over. It seems that self-discharge is influenced by water uptakes. Higher water uptakes mean higher electrolyte uptake resulting in faster vanadium ions diffusion through the electrolyte. The water uptakes of blend membranes are found to be in the order of BM-TMIm $6(58 \%)>$ BM-TMIm 1-1 $(47 \%)>$ BM-TMIm $4(31 \%)$ and self-discharge times were $5.3,38.3,184.3 \mathrm{~h}$, respectively, as shown in Figure 8. Thus, it can be concluded that the AEMs should possess proper water uptakes for VRFB application (it should be noted that a low water uptake leads to a low conductivity).

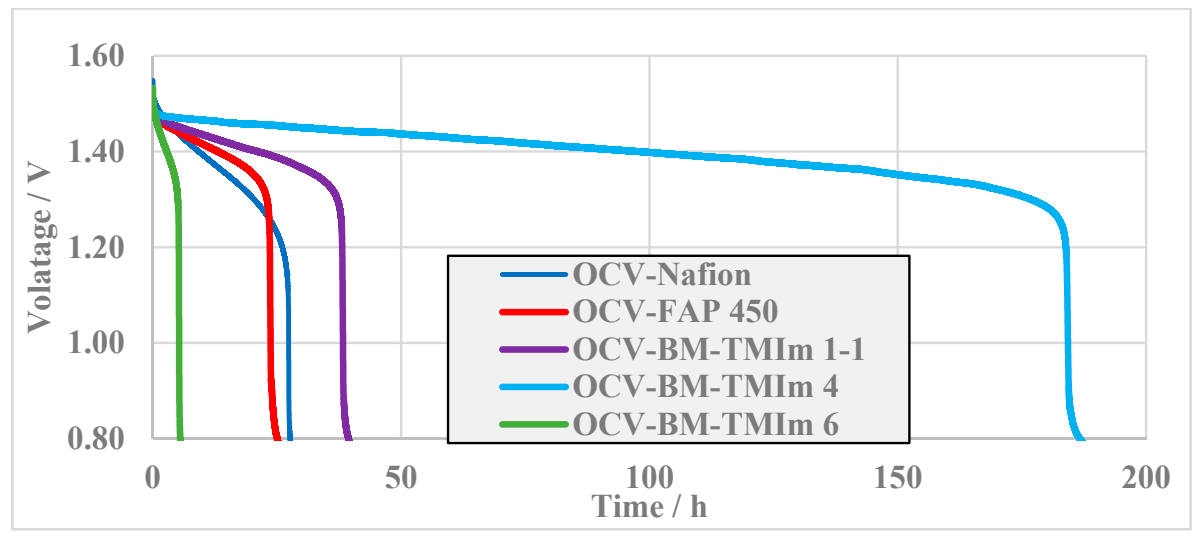

Figure 8. The self-discharge of the VRFBs with different membranes.

To compare the VRFB performance, charging-discharging cycles tests of the two anion-exchange blend membranes BM-TMIm 1-1 and BM-TMIm 6 were conducted (Figure 9). These two were selected to compare the performances of VRFB between 2-component and 3-component blend membranes. The 2-component blend membrane (BM-TMIm 6) almost completely lost its capacity (13\% remaining at 100th cycle), while the 3-component blend membrane BM-TMIm 1-1 had a residual capacity of $72 \%$ after the same number of cycles. This test is correlating with the self-discharge results depicted in Figure 8 . It can be concluded that 3-component blend membranes displayed a significantly reduced vanadium ions cross-over in the VRFB when compared to the 2-component blend membrane. It is clear that the ionical cross-linking via the sulfonated polymer not only enhanced the blocking of vanadium ions but also increased the dimensional stability. 


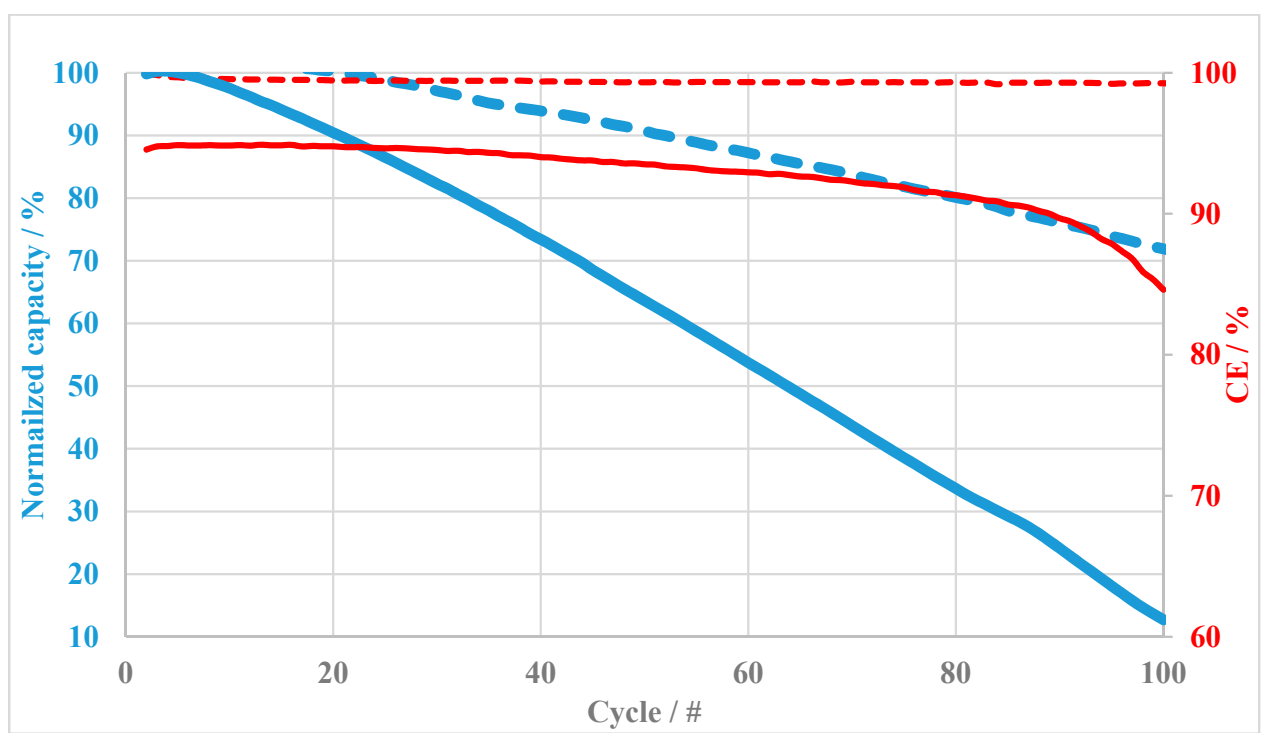

Figure 9. Charging-discharging cycles tests of blend membranes BM-TMIm 1-1 and BM-TMIm 6.

Because BM-TMIm 4 possessed the longest self-discharge time of all the tested membranes in this study, a long-term charging-discharging cycles test was conducted with this blend membrane (Figure 10). It turned out that the coulombic efficiency remained almost 100\% (99.6-99.5\%) over 300 cycles. According to Figures 9 and 10, the BM-TMIm 4 membrane showed less capacity decay than BM-TMIm 1-1. This result suggests that by adjusting anion-exchange polymer proportion in the blend membrane, improved performance in VRFBs can be achieved. According to Figure 10, the capacity retention of BM-TMIm 4 measured at a current density of $40 \mathrm{~mA} / \mathrm{cm}^{2}$ was $95 \%, 86 \%$, and $77 \%$ at the 100th, 200th, and 300th cycle, respectively. Compared with values from other VRFB studies of membranes in the literature, it is obvious that the anion-exchange blend membranes in this study showed improved capacity retention, e.g., when using the imidazole-based amphoteric membrane ImPSf /SPEEK 17\% the capacity retention was $69 \%$ at the 50th cycle with a current density of $80 \mathrm{~mA} / \mathrm{cm}^{2}$ [26], and the capacity retention of an acid-base blend membrane of S/Q-15 was $64 \%$ at the 100th cycle at a current density of $50 \mathrm{~mA} / \mathrm{cm}^{2}$ [27]. The outstanding capacity retention of the anion-exchange blend membrane presented in this study suggests that this membrane type is a promising candidate for vanadium redox flow battery application if the proportion of the components in the blend membrane and the cross-linking density (covalent and/or ionical) is carefully adjusted.

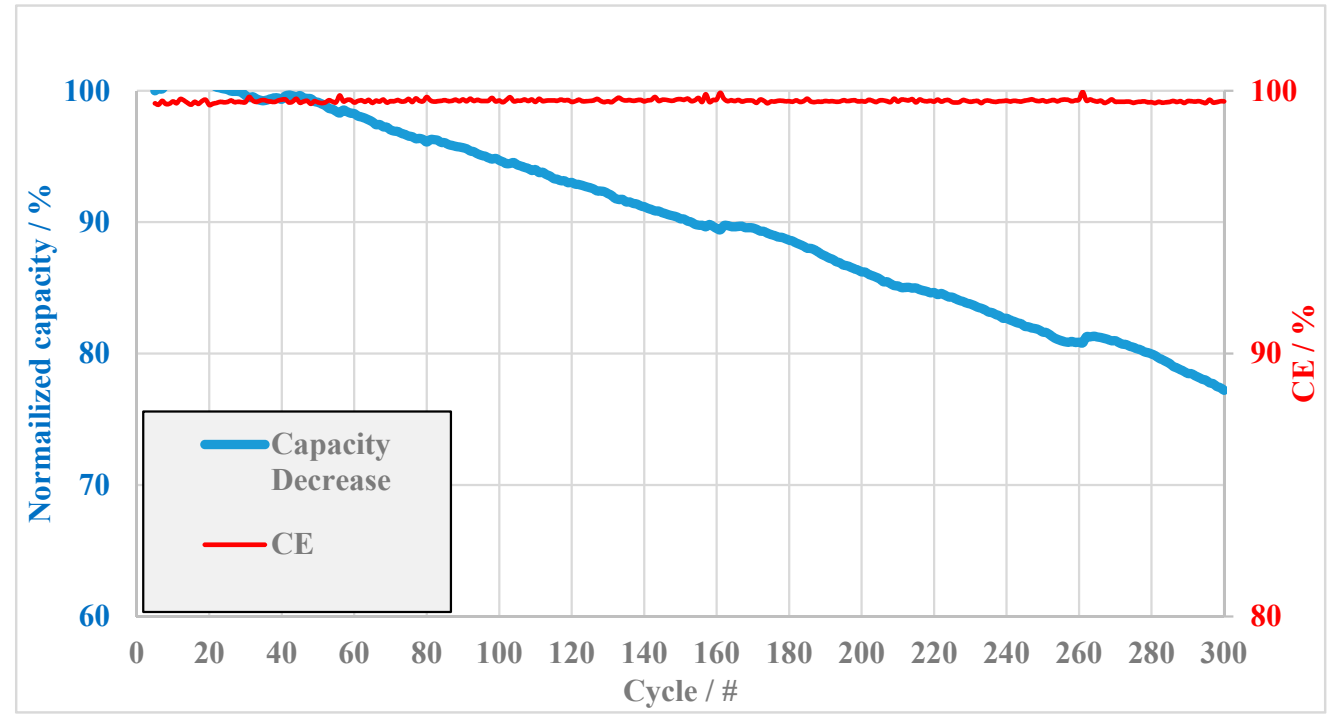

Figure 10. Long-term charging-discharging cycles test with BM-TMIm 4 membrane. 


\section{Conclusions}

A series of anion-exchange blend membranes (AEBMs) having similar thicknesses (wet in $1 \mathrm{M}$ $\mathrm{H}_{2} \mathrm{SO}_{4}$, applied in VRFBs) were fabricated and characterized ex-situ and in-situ in a vanadium redox-flow battery setup. The 3-component AEBMs were composed of bromomethylated PPO, PBI-OO, and a sulfonated polyethersulfone polymer, where the bromomethyl groups of the PPO blend component were quaternized with TMIm. The third component in the blend membranes, the sulfonated polymer, enhanced the chemical stability and dimensional stability of the blend membranes and reduced the vanadium ions cross-over, resulting in improved redox flow battery performance. One of the prepared 3-component blend membranes (BM-TMIm 4) showed an excellent coulombic efficiency of almost $100 \%$ after 300 charging-discharging cycles with a significant capacity retention of $77 \%$ of the initial value after 300 cycles at a current density of $40 \mathrm{~mA} / \mathrm{cm}^{2}$. Therefore, it can be concluded that the investigated 3-component AEBMs are promising candidates for long-term operation as an energy storage system in VRFBs if the proportion and type of the different components in the blend is carefully adjusted. In ongoing research on VRFB membranes, BM-TMIm 5 is showing very long self-discharge time as elucidated in our lab and will be reporting soon along with further types of anion-exchange blend membranes where the type and/or proportion of the different components in the anion-exchange blend membranes, including the type of the halomethylated precursor, the type of the tertiary amine for quaternization, the type of the matrix polymer, and the type of the sulfonated or phosphonated ionically cross-linking polymer, will be varied.

Supplementary Materials: The following are available online at http:/ / www.mdpi.com/2077-0375/8/2/33/s1, Figure S1: Anion exchange blend membranes tested in this study, Figure S2: Comparison of FT-IR spectrum of AEBMs with Br-PPO.

Author Contributions: H.C. and J.K. conceived and designed the experiments. H.C. performed the experiments. H.C., J.K., and H.K. analysed the data. H.C., J.K., and H.K. wrote the paper.

Funding: This research received no external funding.

Acknowledgments: We gratefully acknowledge the valuable help of Inna Kharitonova and Galina Schumsky in performing the membrane characterization experiments and Marcus Mehlhorn for redox flow battery performance measurements.

Conflicts of Interest: The authors declare no conflict of interest.

\section{References}

1. Kim, K.J.; Park, M.-S.; Kim, Y.-J.; Kim, J.H.; Dou, S.X.; Skyllas-Kazacos, M. A technology review of electrodes and reaction mechanisms in vanadium redox flow batteries. J. Mater. Chem. A 2015, 3, 16913-16933. [CrossRef]

2. Rychcik, M.; Robins, R.G.; Fane, A.G. THE New All-Vanadium Redox Flow Cell. J. Electrochem. Soc. 1986, 133, 1057-1058. [CrossRef]

3. Schwenzer, B.; Zhang, J.; Kim, S.; Li, L.; Liu, J.; Yang, Z. Membrane development for vanadium redox flow batteries. ChemSusChem 2011, 4, 1388-1406. [CrossRef] [PubMed]

4. Chen, D.; Wang, S.; Xiao, M.; Meng, Y. Preparation and properties of sulfonated poly(fluorenyl ether ketone) membrane for vanadium redox flow battery application. J. Power Sources 2010, 195, 2089-2095. [CrossRef]

5. Luo, Q.; Zhang, H.; Chen, J.; Qian, P.; Zhai, Y. Modification of Nafion membrane using interfacial polymerization for vanadium redox flow battery applications. J. Memb. Sci. 2008, 311, 98-103. [CrossRef]

6. Xi, J.; Wu, Z.; Teng, X.; Zhao, Y.; Chen, L.; Qiu, X. Self-assembled polyelectrolyte multilayer modified Nafion membrane with suppressed vanadium ion crossover for vanadium redox flow batteries. J. Mater. Chem. 2008, 18, 1232-1238. [CrossRef]

7. Teng, X.; Zhao, Y.; Xi, J.; Wu, Z.; Qiu, X.; Chen, L. Nafion/organically modified silicate hybrids membrane for vanadium redox flow battery. J. Power Sources 2009, 189, 1240-1246. [CrossRef]

8. Wang, N.; Peng, S.; Lu, D.; Liu, S.; Liu, Y.; Huang, K. Nafion/ $/ \mathrm{TiO}_{2}$ hybrid membrane fabricated via hydrothermal method for vanadium redox battery. J. Solid State Electrochem. 2012, 16, 1577-1584. [CrossRef] 
9. Kim, S.; Tighe, T.B.; Schwenzer, B.; Yan, J.; Zhang, J.; Liu, J.; Yang, Z.; Hickner, M.A. Chemical and mechanical degradation of sulfonated poly(sulfone) membranes in vanadium redox flow batteries. J. Appl. Electrochem. 2011, 41, 1201-1213. [CrossRef]

10. Luo, X.; Lu, Z.; Xi, J.; Wu, Z.; Zhu, W.; Chen, L.; Qiu, X. Influences of permeation of vanadium ions through PVDF-g-PSSA membranes on performances of vanadium redox flow batteries. J. Phys. Chem. B 2005, 109, 20310-20314. [CrossRef] [PubMed]

11. Mai, Z.; Zhang, H.; Li, X.; Bi, C.; Dai, H. Sulfonated poly(tetramethydiphenyl ether ether ketone) membranes for vanadium redox flow battery application. J. Power Sources 2011, 196, 482-487. [CrossRef]

12. Kim, S.; Yan, J.; Schwenzer, B.; Zhang, J.; Li, L.; Liu, J.; Yang, Z.; Hickner, M.A. Cycling performance and efficiency of sulfonated poly(sulfone) membranes in vanadium redox flow batteries. Electrochem. Commun. 2010, 12, 1650-1653. [CrossRef]

13. Chen, D.; Hickner, M.A. $\mathrm{V}^{5+}$ degradation of sulfonated Radel membranes for vanadium redox flow batteries. Phys. Chem. Chem. Phys. 2013, 15, 11299-11305. [CrossRef] [PubMed]

14. Chen, D.; Kim, S.; Li, L.; Yang, G.; Hickner, M.A. Stable fluorinated sulfonated poly(arylene ether) membranes for vanadium redox flow batteries. RSC Adv. 2012, 2, 8087-8094. [CrossRef]

15. Chen, D.; Hickner, M.A.; Wang, S.; Pan, J.; Xiao, M.; Meng, Y. Directly fluorinated polyaromatic composite membranes for vanadium redox flow batteries. J. Memb. Sci. 2012, 415-416, 139-144. [CrossRef]

16. Chromik, A.; dos Santos, A.R.; Turek, T.; Kunz, U.; Häring, T.; Kerres, J. Stability of acid-excess acid-base blend membranes in all-vanadium redox-flow batteries. J. Memb. Sci. 2015, 476, 148-155. [CrossRef]

17. Kerres, J.; Cui, W.U.S. Acid-Base Polymer Blends and Their Application in Membrane Processes. U.S. Patent 6194474, 6 July 2004.

18. Kerres, J.; Ullrich, A.; Häring, T. Engineering Ionomer Blends and Engineering Ionomer Blend Membranes. European Patent 1076676, 28 January 2004.

19. Kerres, J.; Zaidi, S.M.J.; Matsuura, T. Blend concepts for fuel cell membranes. In Polymer Membranes for Fuel Cells; Springer: Boston, MA, USA, 2008; pp. 185-221.

20. Mohammadi, T.; Skyllas Kazacos, M. Modification of anion-exchange membranes for vanadium redox flow battery applications. J. Power Sources 1996, 63, 179-186. [CrossRef]

21. Sun, C.N.; Tang, Z.; Belcher, C.; Zawodzinski, T.A.; Fujimoto, C. Evaluation of Diels-Alder poly(phenylene) anion exchange membranes in all-vanadium redox flow batteries. Electrochem. Commun. 2014, 43, 63-66. [CrossRef]

22. Chen, D.; Hickner, M.A.; Agar, E.; Kumbur, E.C. Selective anion exchange membranes for high coulombic efficiency vanadium redox flow batteries. Electrochem. Commun. 2013, 26, 37-40. [CrossRef]

23. Zhang, B.; Zhang, S.; Xing, D.; Han, R.; Yin, C.; Jian, X. Quaternized poly(phthalazinone ether ketone ketone) anion exchange membrane with low permeability of vanadium ions for vanadium redox flow battery application. J. Power Sources 2012, 217, 296-302. [CrossRef]

24. Cha, M.S.; Jeong, H.Y.; Shin, H.Y.; Hong, S.H.; Kim, T.H.; Oh, S.G.; Lee, J.Y.; Hong, Y.T. Crosslinked anion exchange membranes with primary diamine-based crosslinkers for vanadium redox flow battery application. J. Power Sources 2017, 363, 78-86. [CrossRef]

25. Ren, J.; Dong, Y.; Dai, J.; Hu, H.; Zhu, Y.; Teng, X. A novel chloromethylated/quaternized poly(sulfone)/poly(vinylidene fluoride) anion exchange membrane with ultra-low vanadium permeability for all vanadium redox flow battery. J. Memb. Sci. 2017, 544, 186-194. [CrossRef]

26. Yan, X.; Zhang, C.; Dai, Y.; Zheng, W.; Ruan, X.; He, G. A novel imidazolium-based amphoteric membrane for high-performance vanadium redox flow battery. J. Memb. Sci. 2017, 544, 98-107. [CrossRef]

27. Liu, S.; Wang, L.; Li, D.; Liu, B.; Wang, J.; Song, Y. Novel amphoteric ion exchange membranes by blending sulfonated poly(ether ether ketone)/quaternized poly(ether imide) for vanadium redox flow battery applications. J. Mater. Chem. A 2015, 3, 17590-17597. [CrossRef]

28. Katzfuß, A.; Gogel, V.; Jörissen, L.; Kerres, J. The application of covalently cross-linked BrPPO as AEM in alkaline DMFC. J. Memb. Sci. 2013, 425-426, 131-140. [CrossRef]

29. Chromik, A.; Kerres, J.A. Degradation studies on acid-base blends for both LT and intermediate T fuel cells. Solid State Ionics 2013, 252, 140-151. [CrossRef]

30. Li, Q.; Jensen, J.O.; Savinell, R.F.; Bjerrum, N.J. High temperature proton exchange membranes based on polybenzimidazoles for fuel cells. Prog. Polym. Sci. 2009, 34, 449-477. [CrossRef] 
31. Morandi, C.G.; Peach, R.; Krieg, H.M.; Kerres, J. Novel imidazolium-functionalized anion-exchange polymer PBI blend membranes. J. Memb. Sci. 2015, 476, 256-263. [CrossRef]

32. Morandi, C.G.; Peach, R.; Krieg, H.M.; Kerres, J. Novel morpholinium-functionalized anion-exchange PBI-polymer blends. J. Mater. Chem. A 2015, 3, 1110-1120. [CrossRef]

33. Ran, J.; Wu, L.; Varcoe, J.R.; Ong, A.L.; Poynton, S.D.; Xu, T. Development of imidazolium-type alkaline anion exchange membranes for fuel cell application. J. Memb. Sci. 2012, 415-416, 242-249. [CrossRef]

34. Lu, W.; Shao, Z.G.; Zhang, G.; Zhao, Y.; Yi, B. Crosslinked poly(vinylbenzyl chloride) with a macromolecular crosslinker for anion exchange membrane fuel cells. J. Power Sources 2014, 248, 905-914. [CrossRef]

35. Merle, G.; Wessling, M.; Nijmeijer, K. Anion exchange membranes for alkaline fuel cells: A review. J. Memb. Sci. 2011, 377, 1-35. [CrossRef]

36. Chen, D.; Hickner, M.A.; Agar, E.; Kumbur, E.C. Optimized anion exchange membranes for vanadium redox flow batteries. ACS Appl. Mater. Interfaces 2013, 5, 7559-7566. [CrossRef] [PubMed]

37. Kerres, J.; Ullrich, A.; Hein, M.; Gogel, V.; Friedrich, K.A.; Jörissen, L. Cross-linked polyaryl blend membranes for polymer electrolyte fuel cells. Fuel Cells 2004, 4, 105-112. [CrossRef]

38. Tian, B.; Yan, C.W.; Wang, F.H. Modification and evaluation of membranes for vanadium redox battery applications. J. Appl. Electrochem. 2004, 34, 1205-1210. [CrossRef]

39. Liu, H.; Xu, Q.; Yan, C.; Qiao, Y. Corrosion behavior of a positive graphite electrode in vanadium redox flow battery. Electrochim. Acta 2011, 56, 8783-8790. [CrossRef]

40. Chen, D.; Hickner, M.A.; Agar, E.; Kumbur, E.C. Optimizing membrane thickness for vanadium redox flow batteries. J. Memb. Sci. 2013, 437, 108-113. [CrossRef]

41. Cunha, Á.; Martins, J.; Rodrigues, N.; Brito, F.P. Vanadium redox flow batteries: A technology review. Int. J. Energy Res. 2015, 39, 889-918. [CrossRef]

42. Sun, C.; Chen, J.; Zhang, H.; Han, X.; Luo, Q. Investigations on transfer of water and vanadium ions across Nafion membrane in an operating vanadium redox flow battery. J. Power Sources 2010, 195, 890-897. [CrossRef]

(C) 2018 by the authors. Licensee MDPI, Basel, Switzerland. This article is an open access article distributed under the terms and conditions of the Creative Commons Attribution (CC BY) license (http:/ / creativecommons.org/licenses/by/4.0/). 